\title{
ROLE OF PELVIC LYMPHADENECTOMY IN CASES OF GRADE 1 ENDOMETRIAL CANCER
}

By

\section{Mohamed M. Abuhelwa, Mohammed M. Gebril, Maged M. Labib}

Department of Obstetrics and Gynecology, Faculty of Medicine, Al-Azhar University

Corresponding Author: Mohamed Mahmoud Abuhelwa,

Mobile: 01098304483, E-mail: mohamed.abuhelwa@gmail.com

\begin{abstract}
Background: Endometrial cancer (EC) is the most common malignancy of the female reproductive tract. Most patients are diagnosed with an early-stage disease, and the overall survival for stage I in about 85-91\%.

Objective: To assess the role of pelvic lymphadenectomy in management of early stage endometrial carcinoma in order to determine whether the patient is in need to postoperative radiotherapy or not.

Patients and Methods: This was a prospective observational study included 52 postmenopausal patient who complained from vaginal bleeding and underwent endometrial biopsy revealing the presence of endometrial hyperplasia with atypia or grade 1 endometrial adenocarcinoma attended the Gynecological clinic at Maadi Military Hospital Cairo, Egypt from March 2018 to February 2020.

Results: Myometrial invasion in MRI $\neg$ and histopathology was $73.1 \%$ and $65.4 \%$ respectively, with no statistically significant difference. Parametrial invasion was $7.7 \%$ and $9.6 \%$ respectively with no statistically significant difference. Regarding to pelvic nodal invasion in MRI and histopathology, it was $15.4 \%$ and $38.5 \%$ respectively with a statistically significant difference.
\end{abstract}

Conclusion: Pelvic lymphadenectomy demonstrated clinical benefit in patients with early stage endometrial cancer and could be a standard treatment option.

Keywords: Endometrial Cancer, Pelvic Lymphadenectomy, Grade 1 endometrial carcinoma.

\section{INTRODUCTION}

Endometrial cancer (EC) is the most common malignancy of the female reproductive tract. Most patients are diagnosed with an early-stage disease, and the overall survival for stage $I$ in about 85-91\%. Nevertheless, patients with advanced disease and unfavorable pathological characteristics have a guarded prognosis the most significant prognostic factors are histological type and grade, depth of myometrial involvement, lymph vascular invasion, and lymph node (LN) status. $20 \%$ of the patients with EC extending outside of the uterus (stages II and IIIA-B) and $10 \%$ of the patients with clinical stage I disease have LN metastases (LNM) .Therefore, removal of pelvic and paraaortic $\mathrm{LN}$ has been recommended as part of a comprehensive surgical staging including total hysterectomy and bilateral salpingooophorectomy (Siegel et al., 2012).

Histologically it constitutes endometrioid adenocarcinomas grade I and II. Endometrial cancer type II is characterized by rapid tumor progression and a biological behavior often similar to 


\section{MOHAMED M. ABUHELWA et al.,}

ovarian cancer. Histologically it comprises endometroid cancer grade 3 , and other rare histology, e.g. serous cancers, clear cell cancers and carcinosarcoma, mixed Müllerian tumors (Colombo et al., 2015).

Among patients with LNM, paraaortic LN involvement undoubtedly portends a poorer prognosis and occult paraaortic nodal disease becomes a substantial concern. In a retrospective study, Garg et al. (2011) underlined these findings. Among 2559 stage IIIC EC patients, those presenting with paraaortic involvement were more likely to die from their diseases $(\mathrm{HR}=1.40 \mathrm{CI})$. Thus, the FIGO modified its staging of EC and sorted stage IIIC into 2 subgroups according to the paraaortic LN status.

The application of modern imaging tools, like MRI, plays an important role in the preoperative assessment of disease extent and allows the selection of a proper and adequate therapeutic approach for each patient. This way, both the patients requiring a more radical therapeutic approach as well as those who do not require surgery are selected. Internationally, the practice of preoperative MRI evaluation of patients with endometrial cancer differs widely. According to the American College of Radiology (ACR) appropriateness criteria "MRI should be the preferred imaging modality for treatment planning, when available", as it allows best overall assessment of the disease (Lee et al., 2011).

There is increasing evidence that when findings of staging MRI and hysteroscopic biopsy are combined, women at high risk of lymph node metastases can be identified preoperatively. In one study this yielded an accuracy of $81 \%$ and was superior to combined transvaginal sonography (TVS) and hysteroscopic biopsy (Ortoft et al., 2013).

We aimed in this study to assess the role of pelvic lymphadenectomy in management of early stage endometrial carcinoma in order to determine the patients need to postoperative radiotherapy.

\section{PATIENTS AND METHODS}

This was a prospective observational study included 52 patients who attended the Gynecological clinic at Maadi Military Hospital Cairo, Egypt from March 2018 to February 2020.

\section{Inclusion criteria:}

Any postmenopausal patient who complained from vaginal bleeding and underwent endometrial biopsy revealing the presence of endometrial hyperplasia with atypia or grade 1 endometrial adenocarcinoma.

\section{Exclusion criteria:}

1. Other pelvic tumors.

2. Advanced endometrial cancer.

3. Recurrent endometrial carcinoma.

4. Any types of lymphomas or leukemia.

5. Secondary uterine cancer.

All women in the study were subjected to the written consents, full history taking, physical examination and magnetic resonance imaging (MRI) to detect myometrial invasion, parametrial invasion and pelvic nodal invasion. 
Staging of the endometrial cancer was according to FIGO 2009 criteria had been done.

All patients underwent laparotomy for total abdominal hysterectomy (TAH), bilateral salpingo-oophorectomy (BSO), and pelvic lymphadenectomy. Specimen had been examined at the Pathology Department at Maadi Military Hospital to assess the uterus, ovaries and lymph nodes (LNs).

Approvals of the ethical committee, patients were properly counseled as regards the type, methodology and value of study.

\section{Statistical analysis:}

Data were collected throughout history, basic clinical examination; laboratory investigations and outcome measures coded, entered and analyzed using Microsoft Excel software. The data collected were tabulated and analyzed by SPSS (statistical package for the social sciences) version 25 (Armonk, NY: The IBM Corp) on IBM compatible computer. Two types of statistics were done:

- According to the type of data; qualitative data were represented as number and percentage, while quantitative continuous data were represented by mean $\pm S D$.

- Chi-square test $\left(\chi^{2}\right)$ was used for comparison and association between two qualitative variables.

- A P-value of $\leq 0.05$ was considered statistically significant.

\section{RESULTS}

Our results showed that the range of age of studied patients $467-75$ year and mean \pm SD of BMI of patients was 33.1 $\mathrm{kg} / \mathrm{m} 2 \pm 4.9$. As regards parity, $7.6 \%$ was nulliparous, $3.8 \%$ primiparous and $84.6 \%$ multiparous. Also, $53.8 \%$ of patients have hypertension, $28.8 \%$ have Diabetes Mellitus and $5.7 \%$ have hypothyroidism.

The tumor was located in the endometrium in 41 patients, fundal region in 8 patients, lower uterine segment in 2 , and metastatic tumor in the ovary in 1 patient (Table 1).

Table (1): Site of tumor in studied patients

\begin{tabular}{|c|c|c|}
\hline $\begin{array}{ll}\text { Sites } & \text { Cases } \\
\end{array}$ & No & $(\%)$ \\
\hline Endometrium & 41 & $(78.8 \%)$ \\
\hline Fundal & 8 & $(15.5 \%)$ \\
\hline Lower uterine segment & 2 & $(3.8 \%)$ \\
\hline Ovarian metastasis & 1 & $(1.9 \%)$ \\
\hline
\end{tabular}

Table 2, shows that MI in MRI and histopathology was $73.1 \%$ and $65.4 \%$ respectively with no statistically significant difference; parametrial 
invasion was $7.7 \%$ and $9.6 \%$ respectively with no statistically significant difference. Regarding to pelvic nodal invasion in MRI and histopathology, it was $15.4 \%$ and $38.5 \%$ respectively with a statistically significant difference ( $\mathrm{p}$ - value $=0.001$ Table 2).

Table (2): Comparison between MRI and histopathology results

\begin{tabular}{|l|c|c|c|}
\hline Sites & $\begin{array}{c}\text { MRI } \\
(\mathbf{n = 5 2})\end{array}$ & $\begin{array}{c}\text { Pathology } \\
(\mathbf{n = 5 2})\end{array}$ & $\boldsymbol{P}$ - value \\
\hline Myometrial invasion & & & \\
$-\quad$ Less than $50 \%$ & $38(73.1 \%)$ & $34(65.4 \%)$ & $>0.05$ \\
$-\quad$ More than 50\% & $9(17.3 \%)$ & $13(25 \%)$ & \\
\hline Parametrial invasion & $4(7.7 \%)$ & $5(9.6 \%)$ & $>0.05$ \\
\hline Pelvic nodal invasion & $8(15.4 \%)$ & $20(38.5 \%)$ & $\mathbf{0 . 0 0 1}$ \\
\hline
\end{tabular}

As regard to postoperative complication, excessive drain output was $9.6 \%$, paralytic- ileus $1.9 \%$, wound
Infection was $3.8 \%$, Urinary incontinence $1.9 \%$ and incisional hernia was $1.9 \%$ (see Table 3).

Table (3):Postoperative complication in studied patients

\begin{tabular}{|c|c|}
\hline Complications & No $(\%)$ \\
\hline Excessive drain output & $5(9.6 \%)$ \\
\hline Paralytic ileus & $1(1.9 \%)$ \\
\hline Wound Infection & $3(3.8 \%)$ \\
\hline Urinary incontinence & $1(1.9 \%)$ \\
\hline Incisional hernia & $1(1.9 \%)$ \\
\hline
\end{tabular}

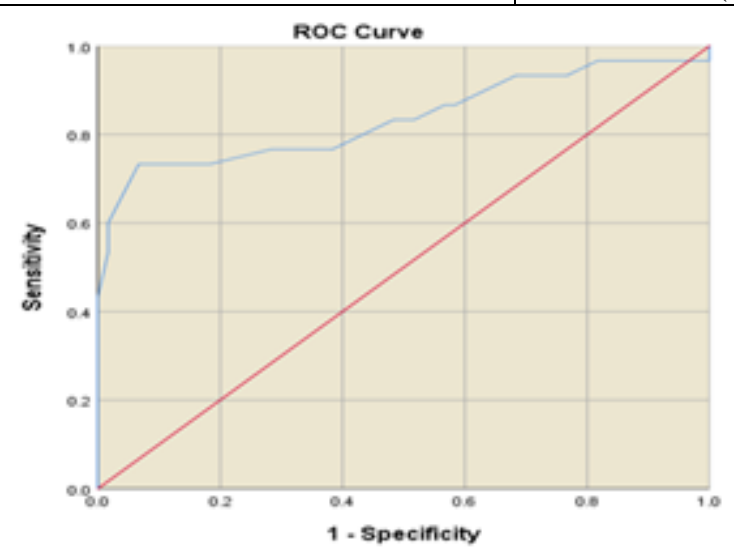

Receiver operating curve (ROC) showed that sensitivity of MRI for detecting pelvic nodal invasion was $78.5 \%$, specificity $73.3 \%$, positive

predictive value $69.4 \%$, negative predictive value $75 \%$ and AUC was 0.836 (Figure 1).

Figure (1): ROC curve of Pelvic nodal invasion by MRI 


\section{DISCUSSION}

Lymphadenectomy is widely used to assess whether endometrial cancer has metastasized and reduces the risk of lymphatic metastasis. Non-systematic lymphadenectomy usually involves removing <11 lymph nodes. However, to try to treat and prevent metastases, physicians often perform systematic lymphadenectomy, which involves removing $\geq 11$ lymph nodes in the same area coveredby non-systematic lymphadenectomy. Systematic lymphadenectomy is significantly more invasive than the non-systematic procedure, and leaves patients with markedly lower postoperative lymph function, increasing the risk of various complications (Zhang et al., 2012).

Theoretically, the removal of lymph nodes has several potential advantages. Complete surgical staging may allow the identification of patients with documented lymphatic dissemination, thus targeting postoperative treatment and potentially reducing the morbidity related to unnecessary radiation therapy. Moreover, lymph node dissection may eradicate metastatic lymphatic disease (Bogani et al., 2014).

In the present study, $88.5 \%$ of patient's preoperative histology of D\& C biopsy was endometrioid, $7.7 \%$ was complex atypical hyperplasia, $1.9 \%$ was scanty tissue and $1.9 \%$ was necrotic tissue.

This was in agreement with the study of Bogani et al. (2014) in which $81 \%$ of patient's preoperative histology of D\& C biopsy was endometrioid, and 19\% were non-endometrioid. Also, Abd El-Wahed et al. (2017) reported in his study that as regard histological data, type I endometrial carcinoma comprised 27 cases of endometrioid adenocarcinoma, six cases of endometrioid carcinoma with squamous differentiation, 15 cases of villoglandular variant of endometrioid carcinoma, and only one case of mucinous adenocarcinoma. Type II endometrial carcinoma comprised six cases of papillary serous adenocarcinoma, six cases of clear cell carcinoma, and six cases of grade III endometrioid carcinoma.

On the other hand, in the present study, we evaluated MRI of patients preoperatively, and found that $73.1 \%$ have myometrial invasion of less than $50 \%$, $17.3 \%$ have MI of more than $50 \%, 7.7 \%$ have parametrial invasion and $15.4 \%$ have pelvic nodal invasion.

In agreement with our study, the study of Bogani et al. (2014) revealed that $77 \%$ have myometrial invasion of less than $50 \%, 23 \%$ have MI of more than $50 \%$. Also, our findings were supported by the study of Rahmani et al. (2018), in which histopathological evaluation showed that $64.4 \%$ of patients had less than $50 \%$ myometrial invasion (superficial myometrial invasion, SMI) and 35.6\% had more than 50\% myometrial invasion (deep myometrial invasion, DMI).

In addition to above findings, in the present study as regard comparison between MRI and histopathology results, we found that MI in MRI and histopathology was $73.1 \%$ and $65.4 \%$ respectively with no statistically significant difference. Parametrial invasion was $7.7 \%$ and $9.6 \%$ respectively with no statistically significant difference. Regarding to pelvic nodal invasion in MRI and histopathology, it was $15.4 \%$ 
and $38.5 \%$ respectively with high statistically significant difference

As regard receiver operating characteristics of pelvic nodal invasion by MRI, we found that sensitivity of MRI for detecting pelvic nodal invasion was $78.5 \%$, specificity $73.3 \%$, positive predictive value $69.4 \%$, negative predictive value $75 \%$ and AUC was 0.836 . The sensitivity for evaluating lymph node metastasis using MR was not high, as MR was capable of finding lymph node metastasis only when nodes were swollen (>10 mm).

\section{CONCLUSION}

Pelvic lymphadenectomy demonstrated clinical benefit in patients with early stage endometrial cancer and could be a standard treatment option.

\section{REFERENCES}

1. Abd El-Wahed MM, Abdou AG, AlSharaky DR and Kasem HA. (2017): Clinicopathological differences between type I and type II endometrial carcinoma. Menoufia Med J., 30:946-51.

2. Bogani, G., Dowdy, S. C., Cliby, W. A., Ghezzi, F., Rossetti, D, and Mariani, A. (2014): Role of pelvic and para-aortic lymphadenectomy in endometrial cancer: current evidence. The journal of obstetrics and gynaecology research, 40(2), 301-311.
3. Colombo N, Creutzberg C, Amant F and Bosse T. (2015): ESMO-ESGO-ESTROn conference on endometrial cancer. In J Gynecol Cancer, 26:2-30.

4. Garg R, Morris T and Solomon L. (2011): Evaluating the significance of location of lymph node metastasis and extranodal disease in women with stage IIIC endometrial cancer, Gynecologic Oncology., 123(2):208-213.

5. Lee JW, Dubinsky $T$, Andreotti $R$ and Cardenes HR. (2011): ACR appropriateness criteria pretreatment evaluation and follow-up of endometrial cancer of the uterus. Ultrasound Q., 27:139-45.

6. Ortoft G, Dueholm M, Mathiesen $O$ and Hansen ES. (2013): Preoperative staging of endometrial cancer using TVS, MRI and hysteroscopy. AOGS., 92:536-45.

7. Rahmani M, Samira H, Azamsadat $M$, Nasrin A, Shilan A and Majid S. (2018): Accuracy of Imaging in Preoperative Local Staging of Endometrial Cancer: Could Imaging Predict Low Risk Patients?, International Journal of Women's Health and Reproduction Sciences., 6 (3):211-9.

8. Siegel R, Naishadham $D$, and Jemal $A$. (2012): Cancer statistics, 2012, CA Cancer Journal for Clinicians., 62(1):10-29.

9. Zhang H, Jia L, Zhang Q, Zhang Y, Yang X and Kong B. (2012): Therapeutic role of systematic retroperitoneal lymphadenectomy in endometrial cancer. Bull Cancer, 99:10-17. 


\section{دراسة دور استنُصال الغدد الليمفاوية الحوضية في حالات المرحلة المبكرة لسرطان بطانة الرحم}

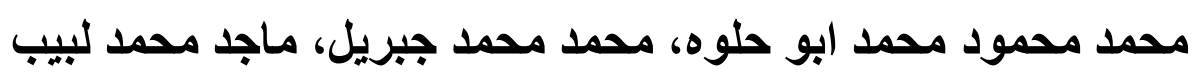
قسم النساء والتوليد، كلية الطب، جامعة الأزهر، القاهرة، مصر

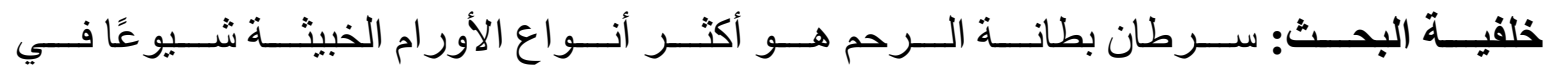

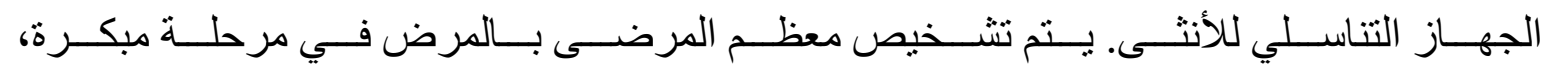

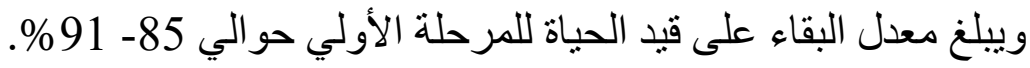

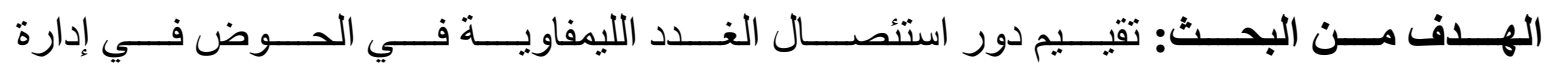

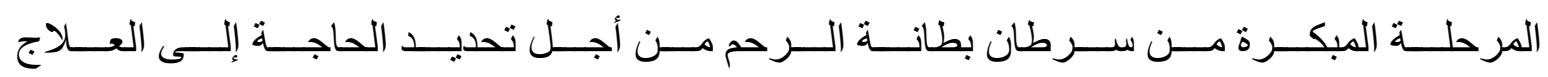
الإشعاعي بعد الحراجة.

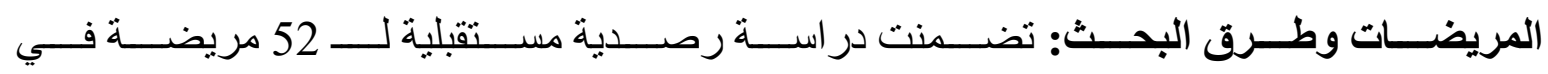

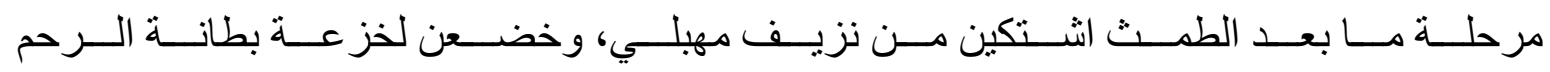

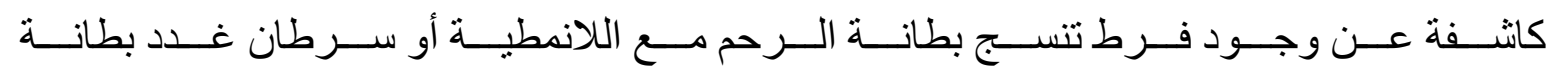

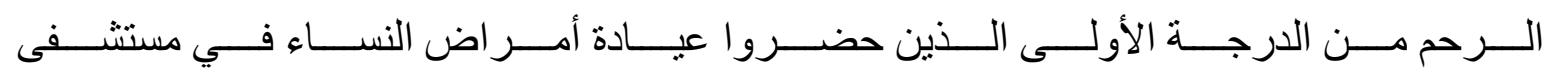
المعادي العسكري بالقاهرة خلال الفترة من مارس 2018 إلى فبر اير الاول 2020.

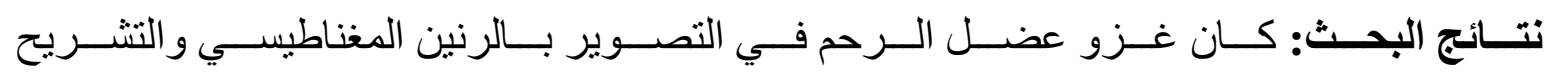

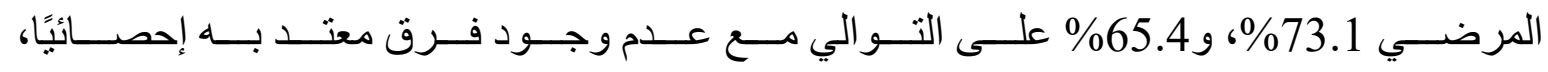

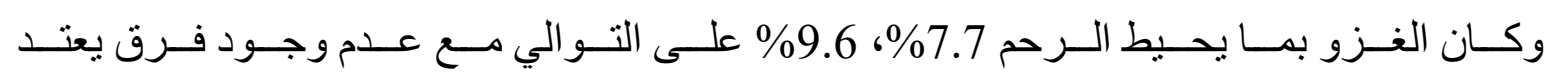

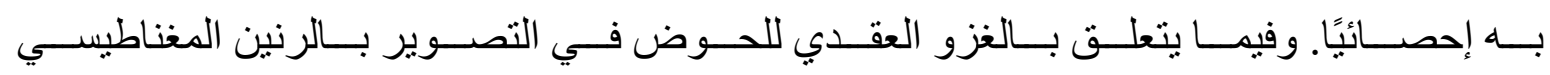

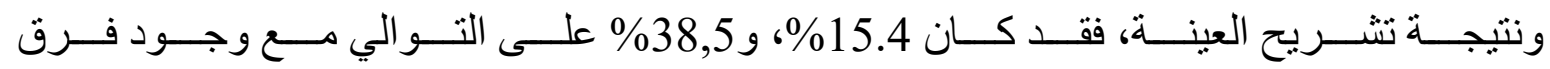
ذو دلالة إحصائية عالية (p-value = 0.001).

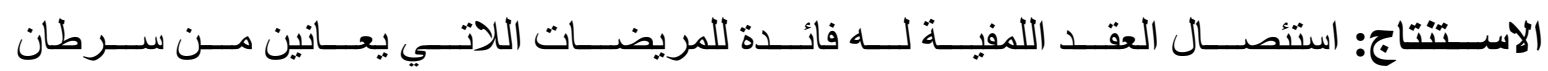
بطانة الرحم في مر احله المبكرة، وبالتالي ينبغي أن يكون خيارًا علاجيًا قياسيًا. 